\title{
Assess the Prevalence and Risk Factor of Hypertension among the Adult at Mandrail in Rajasthan
}

\author{
Vinay Kumar Sharma ${ }^{1}$, Mary Minolin ${ }^{2}$ \\ ${ }^{1}$ B. Sc Nursing, III Year Saveetha University, Chennai 602 105, India \\ ${ }^{2}$ Assistant Professor \& Guide, Saveetha University, Chennai 602 105, India
}

\begin{abstract}
Hypertension is one of the leading causes of death world-wide and is one of the biggest health challenges in the 21st century. Hypertension is defined as a systolic blood pressure above $140 \mathrm{~mm}$ of $\mathrm{Hg}$ or a diastolic pressure above $90 \mathrm{~mm}$ of $\mathrm{Hg}$, based on two or more measurements. Objective: Assess the prevalence of hypertension among the adult Find out the risk factor of hypertension among the adult and associated between level of knowledge among the hypertensive adult with selected demographic variable. Methodology: Descriptive cross sectional research design was adopted. Non probability purposive sampling technique was used to30 hypertensive adult was selected. The data was collected organized and analyzed in term of descriptive statistics Result: The study findings showed that a majority of them i.e. no adequate knowledge, 6[20\%] who had moderate knowledge, 24[80\%] who had inadequate knowledge.
\end{abstract}

Keywords: hypertension, adult.

\section{Introduction}

Hypertension is one of the leading causes of death worldwide and is one of the biggest health challenges in the 21 st century. Hypertension is defined as a systolic blood pressure above $140 \mathrm{~mm}$ of $\mathrm{Hg}$ or a diastolic pressure above $90 \mathrm{~mm}$ of $\mathrm{Hg}$, based on two or more measurements.

As per the World Health Statistics 2012, of the estimated 57 million global deaths in 2008, 36 million (63\%) were due to non communicable diseases (NCDs). The largest proportion of non communicable disease deaths is caused by cardiovascular diseases (48\%). In terms of attributable deaths, raised blood pressure is one of the leading behavioral and physiological risk factor to which $13 \%$ of global deaths are attributed. Hypertension is reported to be the fourth contributor to premature death in developed countries and the seventh in developing countries. Recent reports indicate that nearly 1 billion adults (more than a quarter of the world's population) had hypertension in 2000 , and this is predicted to increase to 1.56 billion by 2025 .

Hypertension increases the risk for a variety of cardiovascular diseases, including, coronary artery disease, heart failure, and peripheral vascular disease.

Coronary disease in men and stroke in women are the principal first cardiovascular events noted after hypertension onset. Hypertension is estimated to affect more than a third of adults aged 25 and above, accounting for about a billion people worldwide and contributes to nearly 9.4 million deaths from cardiovascular diseases each year. The prevalence of hypertension is highest in Africa (46\% of adults) while the lowest prevalence is found in the Americas (35\% of adults).

The prevalence of hypertension is rapidly increasing in developing countries and is one of the leading causes of death and disability. In India, hypertension is the leading non -communicable disease risk and estimated to be attributable for nearly for 10 percentages of all deaths. Adult hypertension prevalence has risen dramatically over the past three decades from 5 percentages to between 20-40 percent in urban areas and 12-17 percent in rural areas. The number of hypertensive individuals is anticipated to nearly double from 118 million in 2000 to 213 million by 2025 .

According to WHO health statistics 2012, the prevalence of hypertension in India was $23.1 \%$ in men and $22.6 \%$ in women in equal or more than 25 years age. The raised blood pressure was a high risk condition that caused approximately $51 \%$ of death from strokes and $45 \%$ from coronary artery disease. It was considered directly responsible for 7.5 million deaths in 2004, about 12.8 percent of the total of all global deaths.

Hypertension has become a significant problem in many developing countries experiencing epidemiological transition from communicable to non-communicable chronic diseases.

The emergence of hypertension and other cardiovascular diseases as a public health problem in these countries is strongly related to the aging of the populations, urbanization, and socioeconomic changes favoring sedentary habits, obesity, alcohol consumption, and salt intake. A costeffective use of health services to control these emerging chronic diseases is particularly needed in developing countries because resources are limited and generally must be shared with the concurrent burden of persistent communicable diseases.

Prevalence of hypertension is high among lower and middle class population set in India. This is mainly attributed to smoking, high alcohol consumption and stress in this set of population. Among the affluent class, physical inactivity and dietary changes are two main causes of hypertension. An

Volume 6 Issue 1, January 2017 


\section{International Journal of Science and Research (IJSR) \\ ISSN (Online): 2319-7064}

Index Copernicus Value (2015): 78.96 | Impact Factor (2015): 6.391

upward trend in consumption of food items like energy drinks and preserved frozen foods are closely related to the increase in blood pressure.

Population based epidemiological studies have reported that all major risk factors especially smoking, obesity, hypertension, hypercholesterolemia and diabetes have increased by $2-5$ times in the country over last 50 years.

Excessive dietary sodium intake contributes to the development of resistant hypertension both through directly increasing blood pressure and by blunting the blood pressure lowering effect of most classes of antihypertensive agents. Obesity is associated with more severe hypertension, a need for an increased number of anti hypertensive medications, and an increased likelihood of never achieving blood pressure control.

An increased level of physical activity can lower blood pressure; independent of concomitant changes in weight. Heavy alcohol intake is associated with both an increased risk of hypertension, as well as treatment- resistant hypertension.

Lifestyle measures for lowering blood pressure include reduced alcohol intake, reduced sodium chloride intake, increased physical activity, and control of overweight. Lifestyle interventions also have the potential to reduce the need for or the amount of medications in hypertensive and prevent high blood pressure from developing in nonhypertensive. Lifestyle interventions are instrumental in controlling other concomitant cardiovascular risk factors not necessarily related to hypertension, such as smoking, raised cholesterol level, or diabetes, hence the importance of a multi factorial approach to effective risk reduction in hypertensive.

\subsection{Statement of Problem}

Assess the Prevalence and Risk Factor of Hyperension among Adult at Mandrail Village in Rajasthan

\subsection{Objective}

- To assess the prevalence of hypertension among the adult

- To assess the risk factor of hypertension among the adult

- To assess the selected demographic variables with the hypertension among the adult

\section{Methodology}

Research approach

A quantitative approach

\section{Research design}

A descriptive cross sectional design.

\section{Setting}

The study will be conducted at Mandrail community area. There is 1500 population. Male is 800 and 700 female written the permission letter and has been obtained from the village precedent to conduct the study

\section{Population}

Hypertensive adult people living in mandrail community area

\section{Sampling techniques}

Non- probability purpose techniques method.

\section{Sample}

35 years above age group residing at mandrail area.

\section{Sample size}

30 sample

\subsection{Criteria for Sampling Technique}

\section{Inclusion criteria}

Both male and female adult with the age group of above 35 years

\section{Exclusion criteria}

Not willing to Participate in the Study

Tool

\section{Description of the Instrument}

The instruments were developed after an extensive review of literature and discussion with experts. a structured questionnaire to asses knowledge was developed. The tool consist of two part,

Part-1

It consist of demographic variables which includes age, sex, income, marital status and occupation

\section{Part-2}

It consists of 15 multiple choice questions related to risk factor of hypertension.

\section{Score interpretation}

Below $50 \%$ inadequate knowledge.

$51-75 \%$ moderately

Above $75 \%$ adequate knowledge.

\section{Data Analysis and Interpretation}

The data obtained were mainly classified into

Section - I:

To determine the distribution of demographic variable

\section{Section- II:}

Distribution of level of knowledge among the prevalence and risk factor of hypertension

\section{Section- III:}

Association between level knowledge and demographic variable.

\begin{tabular}{|c|c|c|c|}
\hline S. No & Level of knowledge & mean & Standard deviation \\
\hline 1 & Knowledge on hhypertension & 8 & 32.63 \\
\hline
\end{tabular}




\section{International Journal of Science and Research (IJSR) \\ ISSN (Online): 2319-7064}

Index Copernicus Value (2015): 78.96 | Impact Factor (2015): 6.391

Frequency and percentage distribution knowledge regarding the hypertension among the hypertensive adult

\begin{tabular}{|c|c|c|c|}
\hline S. No & Level of Knowledge & Frequency & Percentage \\
\hline 1 & Adequate knowledge & 0 & $0 \%$ \\
\hline 2 & $\begin{array}{c}\text { Moderately adequate } \\
\text { Knowledge }\end{array}$ & $\mathbf{6}$ & $20 \%$ \\
\hline 3 & Inadequate knowledge & 24 & $80 \%$ \\
\hline
\end{tabular}

\section{Findings of the Study}

In the study out of 30 adult $0(0 \%)$ of them had adequate knowledge, $6(20 \%)$ of them had moderate adequate knowledge and 24(80\%)of them had inadequate knowledge

The overall knowledge mean score on risk factor among the adult were 43 with mean deviation 8 and standard deviation 32.63

\section{Conclusion}

A non experimental research design was undertaken in the study to assess the prevalence and risk factor of hypertension among the adult age people living in mandrail area.

Samples of 30 adult age people were assessed using Nonprobability convenience sampling technique. Structured self administered questionnaire was by the investigator. The data collection from the sample that mandrail area. The investigator was able to complete the data collection within the stipulated period of 7 days.

\section{References}

[1] Smeltzer S, Bare B, Hinkle J, Cheever K. Brunner \& Suddarth's Text book of Medical Surgical Nursing. $11^{\text {th }}$ Edition .New Delhi :Lippincott Williams \& Wilkins;2009 p. 855-57

[2] Das SK, Sanyal K, Basu A. Study of urban community survey in India: growing trend of high prevalence of hypertension in a developing country. Int $\mathbf{J}$ Med Sci 2005; 2(2):70-8.

[3] Greiw ASH, Gad Z, Mandil A, Wagdi M, Elneihoum A, Greiw ASH. Risk factors for CVD among teachers. [Online]. [Cited 2010]. Available from: URL:www.academicjournals.org/jphe.

[4] Shanthirani CS. Prevalence and risk factors of hypertension in a selected South Indian population--the Chennai Urban Population Study. [Online]. updated 2003 Jan; cited 35]. Available from: URL: www.ncbi.nlm.nih.gov/pubmed/12693449

[5] Yuvaraj BY, Gowda NMR, Umakantha AG. Prevalence, awareness, treatment, and control of hypertension in rural areas of Davanagere. Indian $\mathbf{J}$ Community Med 2010;35:138-41

[6] Gupta R. Trends in hypertension epidemiology in India. Journal of Human Hypertension 2004; 18, 73-78. doi:10.1038/sj.jhh.1001633

[7] Quasem I, Shetye MS,Alex SC. Prevalence, awareness, treatment and control of hypertension among the elderly in Bangladesh and India a multicentre study. Bull World Health Organ 2001;79(6).
[8] Agrawal VK, Bhalwar R, Basannar DR. Prevalence and determinants of hypertension in a rural community. MJAFI 2008;64:21-5 